\title{
Comparative Analysis of The Effects of Short-Term Metformin and Metformin- Insulin Combination on the Liver in Diabetes Wistar Rats
}

\author{
Sahar Mubeen, Rabia Rehan, Sundus Sadia, Iffat Raza, Sarwat Jabeen
}

- - - - - - - - - - - - - - - - - - - - - - - - - ABSTRACT

Objective: To compare the effects of drugs (Metformin and combination) on weight, size and volume of liver in diabetic rats.

Study Design and Setting: This was an experimental comparative study conducted at Institute of Bio Medical Sciences (IBMS), Dow University of Health Sciences (DUHS), Ojha Campus, Karachi.

Methodology: The study was conducted on 40 albino wistar rats. Diabetic rats $(n=20)$ were grouped into 2 . One group was treated with metformin $(n=10)$ while the other group with insulin-metformin combination $(n=10)$ for 4 weeks. All the treated groups were compared with untreated diabetic killed $(n=10)$. After a short period of 4 weeks, all the rats were sacrificed. Livers were isolated, weighed and grossly observed for significant changes. Absolute and mean percent liver weights as well as liver volumeof all rats were calculated.

Results: Data was analyzed by using GraphPad Prism version 5.0.Data for absolute/percent liver weight and liver volume was expressed as Mean \pm SEM. The value obtained was analyzed by Two-way ANOVA followed by Bonferroni test wherever applicable.P-value of $=0.05$ was considered as statistically significant.

Conclusion: The short-term metformin and insulin-metformin treatment doesn't effect liver weight and volume significantly and hence, their short-term use is beneficial in type 2 diabetes.

Key words: Diabetic rats, diabetes type 2, fatty liver ,insulin, liver volume, metformin

\section{INTRODUCTION:}

Diabetes is steadily increasing with an estimated increase from approximately 8.8 percent of global adult population in 2017 to almost 10 percent by the year 2045.It's estimated that the number of diabetic people will rise to 366 million in 2030.The estimated diabetics in the year 2000 is 171 million.

Diabetes is a well-known chronic disorder affecting multiple organs and seriously affecting the quality of life. It can be

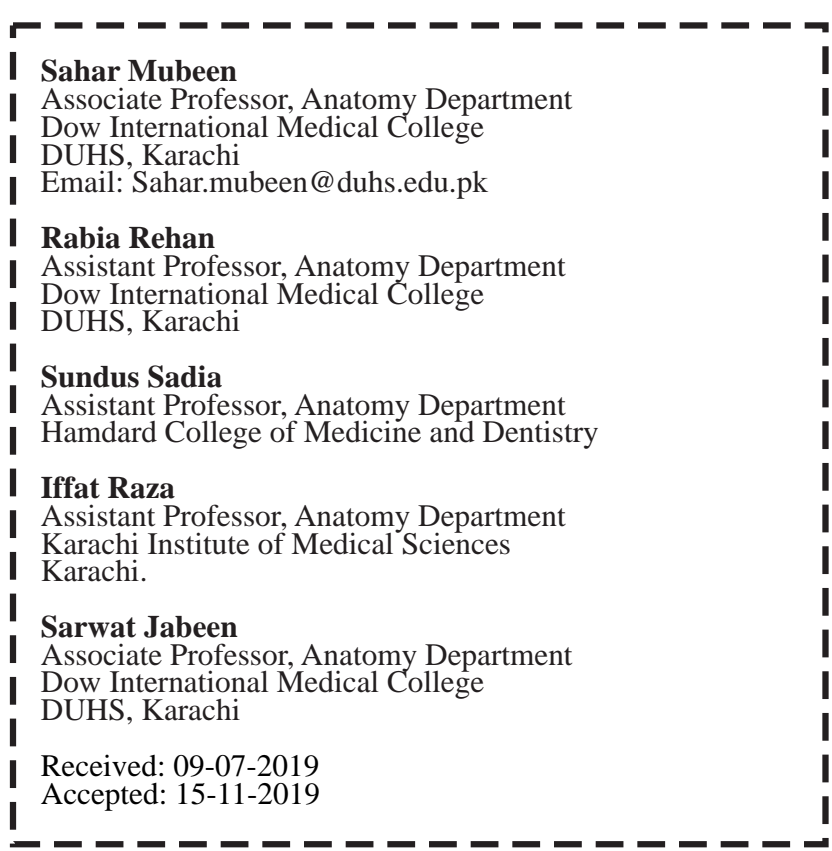

classified into 2 types depending on the absolute or relative deficiency in insulin secretion. This will lead to a cascade of various pathological processes starting from deficient insulin secretion to insulin resistance IR. Uncontrolled diabetes can trigger lethal complications involving almost every organ of the body. Fatty liver disease observed in diabetes is classified as non-alcoholic fatty liver disease (NAFLD) which involves infiltration of hepatocytes with fat progressing slowly from a reversible steatosis to irreversible liver fibrosis and failure. Hepatic Steatosis (HS) is a reversible injury to hepatocytes causing accumulation of fat in the liver replacing functional liver cells. Approximately $78 \%$ diabetics suffer from steatohepatitis which is observable in the liver ultrasound of diabetics. NAFLD progresses silently in diabetics and is frequently overlooked.

Resistance of cells to insulin is the main underlying cause of both DM2 and NAFLD which triggers lipid-accumulation process. This further increase free fatty acid delivery to liver due to mobilization of the peripheral fat.Such histological changes in liver induce hepatic insulin resistance (HIR), further aggravating fat metabolism in liver. A strong association between HS and HIR has already been researched indicating an inverse relation between them; as the body sensitivity to insulin decreases and fat accumulation in liver increases.

Diabetes will remain the focus of research till the scientists discover complete and effective treatment for diabetes. Likewise, anti-diabetics would continue to be under evaluation for their maximum effectiveness and minimum 
side effects. Among anti-diabetics; Insulin and metformin remain frequently prescribed drugs for the clinicians because of their best results in maintaining blood glucose levels. ${ }^{12}$ Both drugs are used as monotherapy as well as in combination. As compared to mono therapy, good results are observed with combination therapy as it keeps in check the liver enzymes as well as blood glucose levels. Insulin when used alone have harmful effects on liver while metformin have good results on liver and blood glucose.

Metformin is well-known for its effectiveness in diabetes type 2 and is proven to be safe as $1^{\text {st }}$ line drug of treatment. The drug causes decreased glucose absorption in the gut and increase in hepatic glucogenesis leading to low blood glucose levels. Moreover, metformin also decreases insulin resistance (IR) by increasing insulin levels and glucose uptake in muscle and adipocytes, hence improving insulin action. The drug also has vital role in decreasing circulating lipids which could be a possible factor required for the management of abnormal liver enzymes and HS.

Keeping in view the above literature search, the present study was aimed to evaluate and compare the effects of drugs (Metformin and combination) on weight, size and volume of liver in diabetic rats.

\section{METHODOLOGY:}

This was an experimental comparative study. Total $(n=40)$ wistar rats were selected via random sampling. Experimental groups were divided into four; each having 10 rats:

Group A [Control]: ( $\mathrm{n}=10)$; Group B [Diabetic]; $(\mathrm{n}=10)$; Group C [Metformin-treated diabetic rats] $(\mathrm{n}=10)$; Group $\mathrm{D}$ [Insulin metformin combination-treated diabetic rats ]$(\mathrm{n}=10)$. Each group was kept in a clear sided plastic cage under suitable room temperature, sunlight and ventilation. All rats were provided with appropriate diet and water ad libitum. Weekly observations of body weight of all rats were carried out via a digital scale till they were sacrificed. Metformin treated rats were given oral metformin in a dose of $200 \mathrm{mg} / \mathrm{kg} / \mathrm{day}$ while combination treated rats were given insulin in adose of $3 \mathrm{U} / \mathrm{kg} / \mathrm{day}$ intraperitoneally while metformin was used in the dose as mentioned previously.Antidiabetic treatment was given for 4 weeks. Afterwards rats were carefully dissected as per standard protocol and liver was isolated. Liver volume of all rats (length $\mathrm{x}$ breadth $\mathrm{x}$ height) were calculated. Absolute liver weight (ALW), relative weight and percent liver weight (PLW) were noted. PLW was calculated using the formula: PLW=weight of liver/body weight x 100. Data for ALW/, PLW and liver volume were expressed as Mean \pm SEM. Graph pad Prism software version 5.0 was used for analysis. ANOVA was applied on the study variables followed by Bonferroni test wherever applicable. P-value of $=0.05$ was considered as statistically significant.

\section{RESULTS:}

Descriptive statistics of all study variables were mentioned in table 1. Group wise comparisons were expressed as mean \pm SEM. Significant difference (P value $<0.01$ ) in ALW was observed in rats that received metformin as compared to untreated group. The ALW was more significant ( $\mathrm{P}$ value $<0.001$ ) in combination treated groups (Graph I). Descriptive statistics revealed that short-term combination treatment has more effective role in reducing ALW as compared to metformin (Table I). However, no significant (P value $>0.05$ ) difference in PLW was observed in all treated groups (Group $\mathrm{C}$ and Group D)as compared to untreated and control group (Graph II). The liver volume was more significant (P value $<0.001$ ) in both Group C and Group D as compared to untreated group (Graph III).

\section{DISCUSSION:}

Research innovation is under a great turmoil to explore the path of cure for numerous untreatable diseases. Diabetes type 2 is one of these diseases which can be controlled with medicines but cannot be treated. Hence, the disease will be in research limelight until the researchers discover its cure.

Graph I: Absolute Liver Weight in all Experimental groups

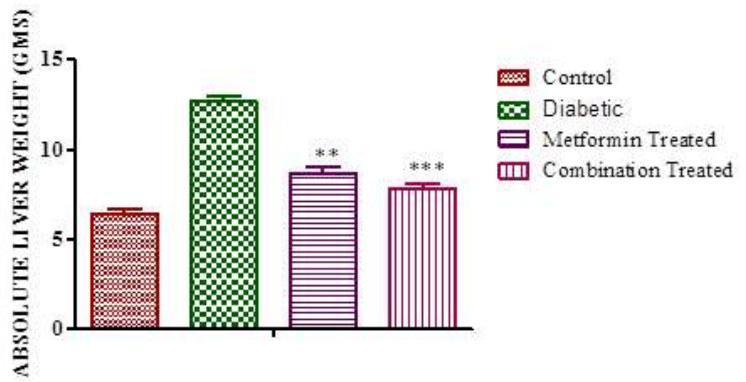

Graph II: Showing Percent Liver Weight in all Experimental groups

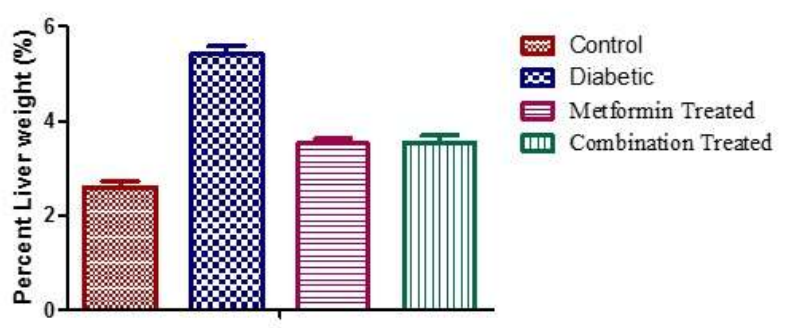

Graph III: Liver Volume in all Experimental groups

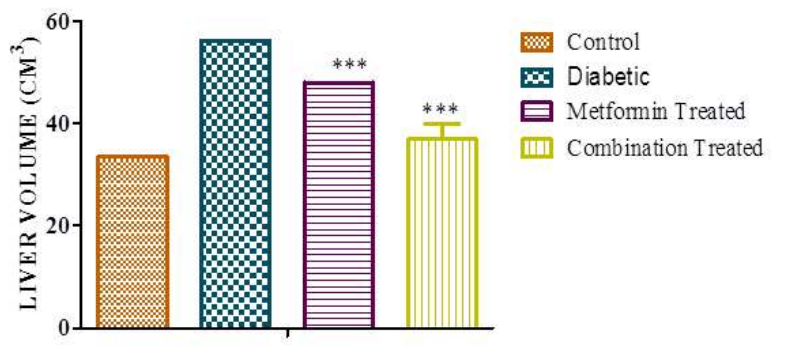


Comparative Analysis of The Effects of Short-Term Metformin and Metformin-Insulin Combination on the Liver in Diabetes Wistar Rats

Table I: Absolute Liver Weight (ALW), Percent Liver Weight (PLW) And Liver Volume In Treated And Untreated Groups In Comparison To Control Group

\begin{tabular}{|l|c|c|c|}
\hline \multicolumn{1}{|c|}{$\begin{array}{c}\text { GROUPS } \\
(\mathbf{n}=\mathbf{4 0})\end{array}$} & $\begin{array}{c}\text { ALW } \\
\text { GMS } \\
\text { MEAN } \pm \text { SEM }\end{array}$ & $\begin{array}{c}\text { PLW } \\
\text { GMS } \\
\text { MEAN } \pm \text { SEM }\end{array}$ & $\begin{array}{c}\text { Liver volume } \\
\text { CM }^{\mathbf{3}} \\
\text { MEAN } \pm \text { SEM }\end{array}$ \\
\hline GROUP A (control) & $6.449 \pm 0.239$ & $2.601 \pm 0.216$ & $33.550 \pm 0.000$ \\
\hline GROUP B (untreated diabetic) & $12.460 \pm 0.361$ & $5.425 \pm 0.159$ & $56.260 \pm 0.000$ \\
\hline GROUP C (metformin treated) & $8.700 \pm 0.300$ & $3.519 \pm 0.109$ & $48.080 \pm 0.000$ \\
\hline GROUP D (insulin-metformin treated) & $7.780 \pm 0.317$ & $3.544 \pm 0.152$ & $36.916 \pm 3.080$ \\
\hline
\end{tabular}

Meanwhile its vital to explore effective medicines with minimum side effects. Metformin and its combination are widely used to control blood glucose levels. The current study is focused on analyzing their effects on absolute and percent weight of liver along with liver volume. Use of either metformin or in combination with insulin has reduced liver volume, absolute and percent liver fat significantly, but combination seems more effective. Also, metformin is widely used in Hepatic Steatosis (HS) of almost all etiologies and has effective results. The results of the study were in comparison with other studies. Findings of the study suggest that the short-term use of insulin metformin combination can be beneficial for diabetic patients and has less side effects on liver cells.

\section{CONCLUSION:}

The short-term use of metformin and metformin-insulin combination in diabetic wistar rats had produced beneficial effects on liver.

\section{REFERENCES:}

1. Diabetes. Percentage of diabetics in the global adult population in 2017 and 2045 2019. Available from: https://www.statista. com/statistics/271464/percentage-of-diabetics-worldwide/.

2. Wild S, Roglic G, Green A, Sicree R, King H. Global prevalence of diabetes: estimates for the year 2000 and projections for 2030. Diabetes care. 2004;27(5):1047-53.

3. Association AD. Diagnosis and classification of diabetes mellitus. Diabetes care. 2014;37(Supplement 1):S81-S90.

4. Srinivasan K, Viswanad B, Asrat L, Kaul C, Ramarao P. Combination of high-fat diet-fed and low-dose streptozotocintreated rat: a model for type 2 diabetes and pharmacological screening. Pharmacological research. 2005;52(4):313-20.

5. Borghi C, Ventura F. Decrease mortality in type II diabetes mellitus: glycemic and renal function control. Journal of Cardiovascular Medicine. 2018;19:e13-e5.

6. Birkenfeld AL, Shulman GI. Nonalcoholic fatty liver disease, hepatic insulin resistance, and type 2 diabetes. Hepatology. 2014;59(2):713-23.

7. Lingvay I, Raskin P, Szczepaniak LS. Effect of insulin-metformin combination on hepatic steatosis in patients with type 2 diabetes. Journal of diabetes and its complications. 2007;21(3):137-42.

8. Bugianesi E, Gastaldelli A, Vanni E, Gambino R, Cassader $\mathrm{M}$, Baldi $\mathrm{S}$, et al. Insulin resistance in non-diabetic patients with non-alcoholic fatty liver disease: sites and mechanisms. Diabetologia. 2005;48(4):634-42.
9. Sorrentino P, Tarantino G, Conca P, Perrella A, Terracciano ML, Vecchione R, et al. Silent non-alcoholic fatty liver disease-a clinical-histological study. Journal of hepatology. 2004;41(5):751-7.

10. Bedossa P. Pathology of non-alcoholic fatty liver disease. Liver International. 2017;37:85-9.

11. Giorda C, Forlani G, Manti R, Mazzella N, De Cosmo S, Rossi MC, et al. Occurrence over time and regression of nonalcoholic fatty liver disease in type 2 diabetes. Diabetes/metabolism research and reviews. 2017;33(4):e2878.

12. Silvares RR, Pereira ENGdS, Flores EEI, Estato V, Reis PA, Silva IJd, et al. Combined therapy with metformin and insulin attenuates systemic and hepatic alterations in a model of highfat diet-/streptozotocin-induced diabetes. International journal of experimental pathology. 2016;97(3):266-77.

13. Abeeleh MA, Ismail ZB, Alzaben KR, Abu-Halaweh SA, AlEssa MK, Abuabeeleh J, et al. Induction of diabetes mellitus in rats using intraperitoneal streptozotocin: a comparison between 2 strains of rats. Eur J Sci Res. 2009;32(3):398-402.

14. Mubeen S, Amjad Z, Memon FM, Ashraf SU. The Short-term Effects of Insulin, Metformin and Insulin-Metformin Combination on the Liver Morphology in High Fat Diet/Streptozotocin Induced Diabetic Albino Rats. Journal of the College of Physicians and Surgeons--Pakistan: JCPSP. 2016;26(12):962-6.

15. Maruthur NM, Tseng E, Hutfless S, Wilson LM, SuarezCuervo C, Berger Z, et al. Diabetes medications as monotherapy or metformin-based combination therapy for type 2 diabetes: a systematic review and meta-analysis. Annals of internal medicine. 2016;164(11):740-51.

16. Eriksson A, Attvall S, Bonnier M, Eriksson JW, Rosander B, Karlsson FA. Short-term effects of metformin in type 2 diabetes. Diabetes, obesity and metabolism. 2007;9(3):3306.

17. Dmitri K, McFarlane Samy I, Sowers James R. Metformin: an update. Ann Intern Med. 2002;137(1):25-33.

18. Hundal RS, Krssak M, Dufour S, Laurent D, Lebon V, Chandramouli V, et al. Mechanism by which metformin reduces glucose production in type 2 diabetes. Diabetes. 2000;49(12):2063-9.

19. Hattori Y, Suzuki K, Hattori S, Kasai K. Metformin inhibits cytokine-induced nuclear factor êB activation via AMPactivated protein kinase activation in vascular endothelial cells. Hypertension. 2006;47(6):1183-8.

20. Forcheron F, Abdallah P, Basset A, Del Carmine P, Haffar G, Beylot M. Nonalcoholic hepatic steatosis in Zucker diabetic rats: spontaneous evolution and effects of metformin and fenofibrate. Obesity. 2009;17(7):1381-9. 
21. Nobili V, Manco M, Devito R, Di Ciommo V, Comparcola D, Sartorelli MR, et al. Lifestyle intervention and antioxidant therapy in children with nonalcoholic fatty liver disease: a randomized, controlled trial. Hepatology. 2008;48(1):119-28.

22. Sagi R, Reif S, Neuman G, Webb M, Phillip M, Shalitin S. Nonalcoholic fatty liver disease in overweight children and adolescents. Acta Paediatrica. 2007;96(8):1209-13.

23. Spruss A, Kanuri G, Stahl C, Bischoff SC, Bergheim I. Metformin protects against the development of fructoseinduced steatosis in mice: role of the intestinal barrier function. Laboratory investigation. 2012;92(7):1020.
24. Rojas LBA, Gomes MB. Metformin: an old but still the best treatment for type 2 diabetes. Diabetology \& metabolic syndrome. 2013;5(1):6.

25. Tiikkainen M, Häkkinen A-M, Korsheninnikova E, Nyman T, Mäkimattila S, Yki-Järvinen H. Effects of rosiglitazone and metformin on liver fat content, hepatic insulin resistance, insulin clearance, and gene expression in adipose tissue in patients with type 2 diabetes. Diabetes. 2004;53(8):2169-76.

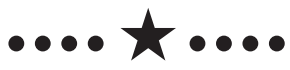

